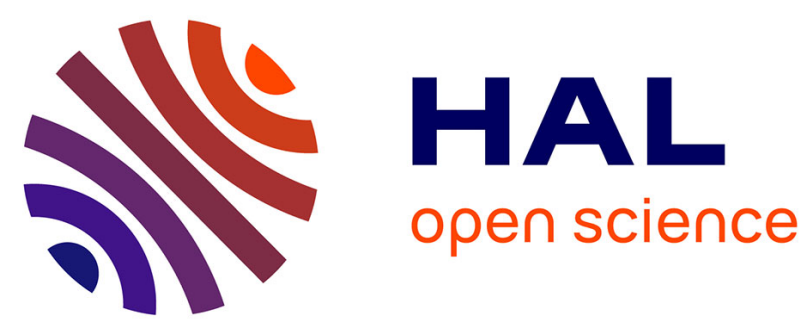

\title{
NEW ATTEMPT TO DETERMINE THE FREE NEUTRON LIFE TIME BY IN-BEAM DETECTION OF DECAY ELECTRONS
}

P. Liaud, K. Schreckenbach, J. Chauvin, P. de Saintignon, A. Bussière

\section{- To cite this version:}

P. Liaud, K. Schreckenbach, J. Chauvin, P. de Saintignon, A. Bussière. NEW ATTEMPT TO DETERMINE THE FREE NEUTRON LIFE TIME BY IN-BEAM DETECTION OF DECAY ELECTRONS. Workshop on Reactor Based Fundamental Physics, 1983, Grenoble, France. pp.C3-37-C3-40, 10.1051/jphyscol:1984308 . jpa-00224022

\section{HAL Id: jpa-00224022 https://hal.science/jpa-00224022}

Submitted on 1 Jan 1984

HAL is a multi-disciplinary open access archive for the deposit and dissemination of scientific research documents, whether they are published or not. The documents may come from teaching and research institutions in France or abroad, or from public or private research centers.
L'archive ouverte pluridisciplinaire HAL, est destinée au dépôt et à la diffusion de documents scientifiques de niveau recherche, publiés ou non, émanant des établissements d'enseignement et de recherche français ou étrangers, des laboratoires publics ou privés. 


\title{
NEW ATTEMPT TO DETERMINE THE FREE NEUTRON LIFE TIME BY IN-BEAM DETECTION OF DECAY ELECTRONS
}

\author{
P. Liaud, K. Schreckenbach ${ }^{\star}$, J. Chauvin ${ }^{\star \star}$, P. de Saintignon ${ }^{\star \star}$ and A. Bussière ${ }^{\star \star \star}$ \\ Faculté des Sciences de Cham béry, B.F. 1104, 73011 Cham béry Cedex, France \\ and Institut Laue-Langevin, 156X, 38042 Grenoble Cedex, France \\ *Institut Laue-Langevin, 156x, 38042 Grenoble Cedex, France \\ * Institut des Sciences Nucléaires, avenue des $M$ artyrs, \\ 38026 Grenoble Cedex, France \\ *** aboratoire de Physique des Particules, B.P. 909, \\ 74019 Annecy le Vieux Cedex, France
}

RESUME - Une mesure de la durée de vie du neutron est en préparation. Le nombre d'électrons se désintégrant par unité de temps $\left(\frac{\Delta \mathrm{N}_{e}}{\Delta t}\right)$ est obtenu en observant 1a désintégration d'un faisceau haché de neutrons froids passant à travers un compteur proportionnel à migration rempli de He $e^{4}$. Le nombre de neutrons susceptibles de se désintégrer $\left(\mathrm{N}_{\mathrm{n}}\right)$ est obtenu par la mesure de 1 'activité d'un échantillon de $\mathrm{Co}^{59}$ absorbant totalement le faisceau de neutron ; $\lambda=\frac{1}{\mathrm{~N}_{\mathrm{n}}}\left(\frac{\Delta \mathrm{N}_{\mathrm{e}}}{\Delta \mathrm{t}}\right)$.

ABSTRACT - A measurement of the half life of the neutrons is in progress. Bursts of cold neutrons are passed through a ${ }^{4}$ He proportional counter (drift chamber) and the number $\Delta \mathrm{N}_{\mathrm{e}}$ of betas from the decaying neutrons are measured in $4 \pi$ geometry during an interval $\Delta t$ in the chamber. The total number $N_{n}$ of neutrons per burst is determined by activation analysis of the ${ }^{59}$ Co beam catcher, resulting in the decay constant $\lambda=\frac{1}{N_{n}}\left(\frac{\Delta N_{e}}{\Delta t}\right)$.

The importance of precise knowledge of the half life of the neutron is akin to that of the fundamental constants. Measurements of this quantity are of great importance to $\beta$ decay theory and have far reaching consequences in cosmology $/ 1 /$.

The following table summarizes the values of $\left|g_{A} / g_{V}\right|$ from the measurements of the 1 ife time $\tau_{n}$ of the neutron :

$\begin{array}{lll}(1959) & \text { Sosnovski } & 1.17 \pm 0.019 \\ (1972) & \text { Christensen } & 1.243 \pm 0.011 \\ (1978) & \text { Bondarenko } & 1.279 \pm 0.006 \\ (1980) & \text { Byrne } & 1.230 \pm 0.014 \\ (1978) & \text { Paul } & 1.255 \pm 0.055 \\ (1980) & \text { Kosvintsev } & 1.287 \pm 0.077\end{array}$

The angular correlation measurements are consistent together and lead to an averaged value :

$$
\mathrm{g}_{\mathrm{A}} / \mathrm{g}_{\mathrm{V}}=1.258 \pm 0.0085 / 2 /
$$

in contrast to the inconsistency of the $\tau$ measurements. In the beta decay of nuclei the axial coupling constant $g_{A}$ undergoes an extra renormalization due to the meson exchange current so that the value of $g_{A}$ inferred from the neutron decay is used :

- to test the PCAC theory

- to calculate the Cabibbo angle 
The $\mathrm{g}_{\mathrm{A}} / \mathrm{g}_{\mathrm{V}}$ ratio of the coupling constants of the $\beta$ decay can be written in term of the (ft) value of the $0^{+} \rightarrow 0^{+}$and neutron decay.

$$
\begin{aligned}
& \frac{1+3\left(\mathrm{~g}_{\mathrm{A}} / \mathrm{g}_{\mathrm{V}}\right)^{2}}{2}=\frac{(\mathrm{ft}) \mathrm{O}^{+} \rightarrow \mathrm{O}^{+}}{(\mathrm{ft}) \text { neutron }} \\
& \text { where }(\mathrm{ft})_{\mathrm{O}^{+}} \rightarrow \mathrm{O}^{+}=3084 \pm 1.9 \mathrm{~s}
\end{aligned}
$$

Thus the precision of the (ft) value of the neutron decay is actually limited by the measurements of the neutron half life.

The basic arrangement of our method is shown in fig. 1. A monochromator deflects neutrons under a right angle out of the cold neutron beam PN7. A double chopper assembly. forms neutron bursts of about $25 \mathrm{~cm}$ length. The bursts enter a ${ }^{4} \mathrm{He}$ filled proportional counter which is layed out as a drift chamber. The activity of the ${ }^{59} \mathrm{Co}$ beam catcher is a measure for the number of neutrons per burst. The background can be measured when the burst travels outside of the counter. Fig. 2 illustrates the expected signal from the counter. The decay constant $\lambda$ is given by

$$
\lambda=-\frac{1}{N_{n}} \frac{\Delta N_{e}}{\Delta t}
$$

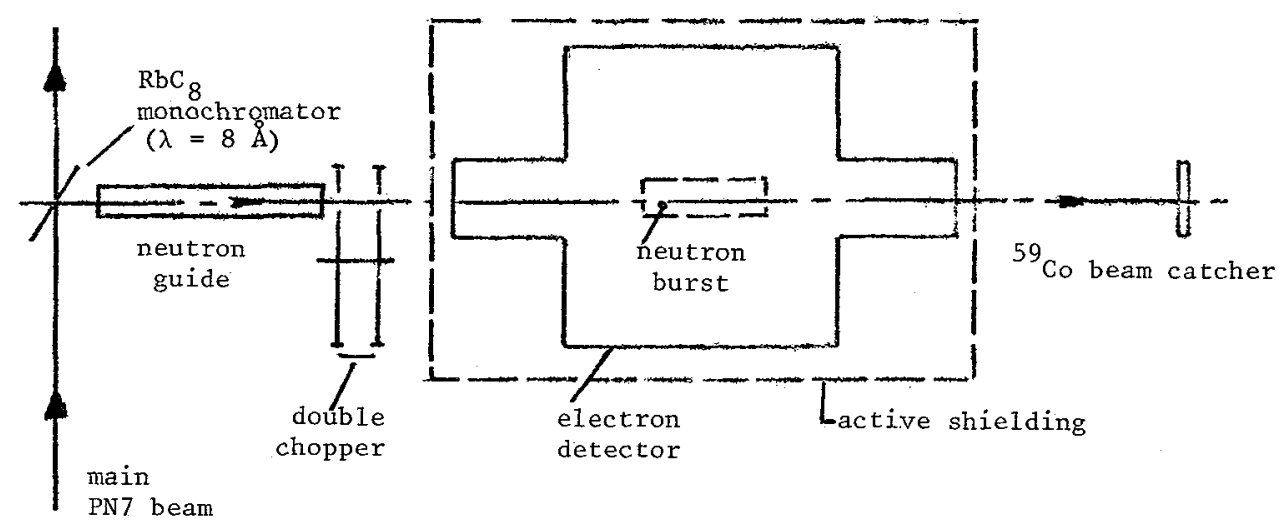

Fig. 1 - Scheme of the experimental set-up

\section{The neutron beam}

The neutron monochromator is made of $\mathrm{a}_{0} \mathrm{RbC}_{8}$ crystal of $3 \times 5 \mathrm{~cm}^{2}$ size and deflect under a Bragg angle of $2 \Theta=90^{\circ}$ a $\lambda=8$ A beam with a resolution of $\Delta \lambda / \lambda=3 \%$. The neutrons are guided and collimated by a bunch of parallel Pyrex tubes of 10 mm $\emptyset$. The flux at the exit of such a guide (divergency $\sim 0.5^{\circ}$ ) was measured as $\phi=2-3 \times 10^{6} \mathrm{n} \mathrm{cm}^{-2} \mathrm{sec}^{-2}$. The doub1e chopper, distant by $70 \mathrm{~cm}$, will filter out higher orders of reflection and block the direct view to the monochromator (source of $\gamma$ and $\mathrm{e}^{-}$background). 


\section{Electron detection}

The electron detector is a classical drift chamber filled at atmospheric pressure with a ${ }^{4} \mathrm{He}(95 \%) \mathrm{CO}_{2}(5 \%)$ gas mixture.

The ionization due to the $\beta$ decay of the neutron is drawn by a convenient electrical field to the multiwires proportional part (MWPC) where the avalanches take place.

First measurements done with a prototype of the electron detector gave an efíiciency close to $100 \%$ for both the MWPC part and the drift part.

The fig. 3 shows a typical result obtained by a coincidence measurement of the chamber as a transmission counter and a scintillator.

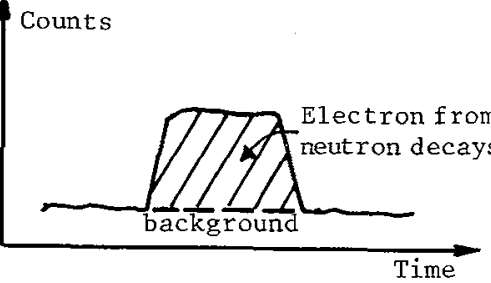

Fig. 2 - Time spectrum of the electron detector triggered by the chopper

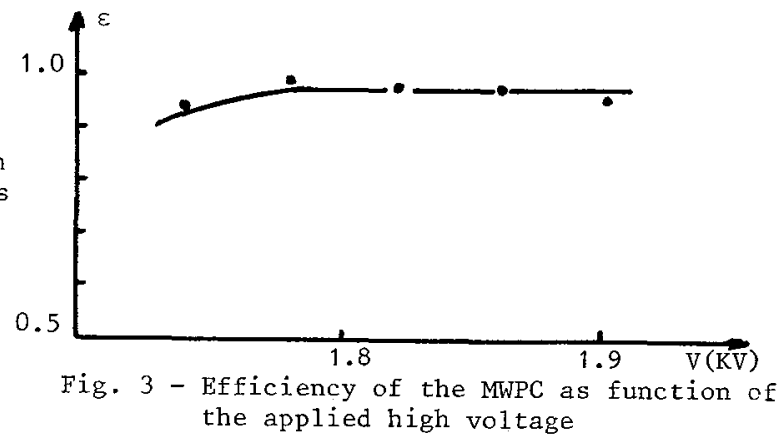

The cosmics rays and radiations from neighbouring experiments are screened by a veto signal from plastic scintillators surrounding the electron detector.

The elastically scattered neutrons in the ${ }^{4}$ He gas may cause $(n, \gamma)$ processes in the detector materials. The use of graphite for the electrode frames and for the cladding of the gas box, as well as the use of Zirconium wires limit this background contribution to less than 0.1 of the event rate. In order to avoid neutron captures in the counter itself the ${ }^{4} \mathrm{He}$ gas has to be free of ${ }^{3} \mathrm{He}$; the $\mathrm{He}^{3} / \mathrm{He}^{4}$ ratio must be smaller than $5 \times 10^{-10}$.

To suppress further the background, the path. of the emitted electrons is recorded, thus the origin of the electron path can be located and sparking of individual wires recognized.

As the ionisation level is very low $(0.25 \mathrm{keV} / \mathrm{cm}$ of gas) we also foresee to insert between the drift and the MWPG parts a gas preamplifier stage $/ 3 /$.

\section{Neutron flux measurement}

For most of the neutron life time experiments done until now the neutron flux density had to be measured by rather delicate methods (transmission counter using ${ }^{3} \mathrm{He}$ or $\left.{ }^{10} \mathrm{~B}\right)$. For our arrangement the total number of neutrons is the relevant value which must be determined.

This measurement can be accomplished by absorbing a11 neutrons of a burst in a ${ }^{59}$ Co sample of a thickness of $3 \mathrm{~mm}$. The prompt $\gamma$-rays from the ( $\mathrm{n}, \gamma$ ) reaction are recorded in a $\mathrm{Ge}(\mathrm{Li})$ detector. The absolute efficiency $\varepsilon$ of this arrangement can 
be determined in replacing the beam catcher by a ${ }^{60}$ Co sample of well-known activity. Thus the neutron flux measurement can be done also on-1ine :

$$
\phi_{\mathrm{n}}=\frac{\mathrm{n}_{\gamma}}{\varepsilon_{\gamma} \cdot n_{\gamma}}
$$

where $n_{\gamma}$ are the detected events of a prompt $\gamma 1$ ine. $n_{\gamma}$ is the intensity of this line per $n$ capture as determined by a calibration measurement $/ 4 / \varepsilon_{\gamma}$ is the efficiency at $E_{\gamma}$. A strong prompt $\gamma$ line is observed at $1215 \mathrm{keV}$, which is close to the $\gamma$ energies following the beta decay of ${ }^{60} \mathrm{Co}$, thus $\varepsilon_{\gamma} \approx \varepsilon$ for this 1 ine.

In addition the accumulated neutron flux can be determined off-line with 6 high precision by activation analysis of the beam catcher, i.e. the produced ${ }^{60}$ Co activity. In a preliminary stage of the experiment the neutron flux could also be determined by a ${ }^{6}$ Li drifted glass scintillator as beam catcher.

\section{Conclusion}

Since the first measurement of the neutron half life, the general trend for neutron beam experiments went towards shorter half life values with improved technics. The present method, which differs vastly from those beam measurements, avoid some of the previous technical problems and will hopefully give a value with a high level of confidence.

/1/ Tayler R.J., Nature, vol 282 (Dec. 1979)

/2/ Wilkinson D.H., Progress in particule and nuclear physics $\underline{6}$ (1980) 325

/3/ Marchand P., Thesis LAPP Annecy le Vieux

14/ Schreckenbach K., et a1., Internal report ILL (Dec. 1981) 